\title{
Nitric oxide modulates expression of extracellular matrix genes linked to fibrosis in kidney mesangial cells
}

\section{Javid Wani, Marina Carl, Anna Henger, Peter J. Nelson* and Harald Rupprecht}

Medical Policlinic, Ludwig Maximilians University, Schillerstrasse 42, D-80336 Munich, Germany

${ }^{*}$ Corresponding author

e-mail: peter.nelson@med.uni-muenchen.de

\begin{abstract}
Mesangial cells are thought to be important mediators of glomerular inflammation and fibrosis. Studies have established a direct role for nitric oxide (NO) in the regulation of gene expression in mesangial cells. Representational difference analysis was used to investigate changes in gene expression elicited by the treatment of $S$-nitroso-L-glutathione in rat mesangial cells. Seven upregulated and 11 downregulated genes were identified. Four out of 11 downregulated genes (connective tissue growth factor, thrombospondin-1, collagen type I $\alpha 1$ and collagen type I $\alpha 2$ ) are known to be linked to inflammation and fibrosis. Results were verified across species in mesangial cells treated with a series of NO donors using Northern blot analysis, quantitative real-time PCR and protein analysis methods. Induction of endogenous NO production by cytokine stimulation also triggered regulation of the genes. One example gene, connective tissue growth factor, was studied at the promoter level. Promoter-reporter gene studies in mesangial cells demonstrated that NO acts at the transcriptional level to suppress gene expression. Our results reveal a complex role of NO in regulating gene expression in mesangial cells and suggest an antifibrotic potential for NO.
\end{abstract}

Keywords: connective tissue growth factor (CTGF); extracellular matrix; mesangial cells; nitric oxide; representational difference analysis (RDA); transcriptional regulation.

\section{Introduction}

Nitric oxide (NO) is a major signal transduction molecule in vertebrates. NO is produced in response to stress (Ohno et al., 1993) and can lead to tissue injury because of its radical chemistry, or be cytoprotective by destroying pathogenic microorganisms (Guzik et al., 2003). NO causes the relaxation of vascular smooth muscles (Blatter and Wier, 1994) and has antiproliferative effects on mesangial cells (Rupprecht et al., 2000). Interactions of mesangial cells (MCs) with components of the extracellular matrix (ECM) influence MC attachment, contraction, migration, survival and proliferation. MCs are thought to be important mediators of glomerular inflammation and fibrosis via their proliferative and secretory potential.
ECM deposition leads to glomerular inflammation and fibrosis. Recent studies have identified a direct role for $\mathrm{NO}$ in the regulation of gene expression in different cell types, including MCs. However, the extent and level at which NO regulates the expression of ECM genes in MCs have not been systematically evaluated. NO has been shown to activate diverse signaling pathways that affect gene expression in mammalian cells (Hemish et al., 2003). NO elicits changes in gene expression in rat MCs and regulates the transcription of genes such as MIP-2, MMP-9, SPARC, biglycan, IAP, HO-1 and Cu/Zn-SOD (Bogdan, 2001; Pfeilschifter, 2002).

Glomerulonephritis progresses through the accumulation of ECM and results in loss of the glomerular architecture and scarring (Habib, 1975; Rosenberg, 1986; Oguma, 1988; Stengel, 2003). The pathogenesis of glomerulonephritis is incompletely understood, but the eliciting factor is thought to be an immunological injury to resident cells in the glomeruli, e.g., MCs or podocytes. In several animal models of chronic renal disease and glomerular inflammation, an increase in NO synthesis on administration of L-arginine has been shown to decrease the degree of glomerulosclerosis, reduce matrix score and attenuate focal glomerulosclerosis (reviewed by Groves and Wang, 2000).

Endogenously synthesized NO can prevent endotoxininduced glomerular thrombosis (Shultz and Raij, 1992). NO generated by the activation of iNOS has also been shown to have a protective role against tubulointerstitial injury and cytokine production in adriamycin nephropathy (Rangan et al., 2001). Inhibition of iNOS in a rat model of autoimmune interstitial nephritis showed host-protective effects of endogenously generated NO in an organspecific manner (Gabbai et al., 1997).

To determine the extent to which NO regulates gene expression in MCs, we used a PCR-based representational differential analysis (RDA) (Pastorian et al., 2000; Hubank et al., 2004) technique in S-nitrosoglutathione (GSNO)-treated rat MCs. To determine the level at which these genes are regulated, we carried out mRNA half-life and promoter experiments with one of the candidate ECM genes, connective tissue growth factor (CTGF), in rat and human MCs.

\section{Results}

\section{Identification of genes differentially regulated by NO}

To identify genes differentially expressed by NO, MCs were treated with $500 \mu \mathrm{M}$ GSNO for $4 \mathrm{~h}$. PolyA ${ }^{+}$RNA was isolated from control and GSNO-treated cells and reverse-transcribed into cDNA. The cDNA was subtracted by representational difference analysis (RDA) and 51 clones were isolated: 23 clones from subtraction pool A 
Table 1 List of differentially expressed genes in GSNO-treated rat mesangial cells.

\begin{tabular}{ll}
\hline Pool 'A' or upregulated genes & GenBank accession no. \\
\hline Pyruvate kinase, muscle $(P k m)$ & NM_053297 \\
Hemochromatosis (Hfe) & NM_053301 \\
ATPase synthase subunit 6 & AF504920 \\
Tyrosine 3-monooxygenase (Ywahab) & NM_019377 \\
Integrin $\beta$ 1 (ltgb1) & NM_017022 \\
Aldose reductase (Akr1b10) & NM_001013084 \\
Triosephosphate isomerase (Tpi1) & NM_022922 \\
& \\
Pool 'B' or downregulated genes & NM_134353 \\
Poly(A) binding protein 1 (Pabpc1) & AF309630 \\
Thrombospondin-1 (TSP-1) & NM_022266 \\
Connective tissue growth factor (CTGF) & Z78279 \\
Procollagen type 1 $\alpha 1$ (COL1A1) & NM_0253356 \\
Procollagen type 1 $\alpha 2$ (COL1A2) & NM_022245 \\
Mitochondrial cytochrome B5 (Cyb5) & XM_223327 \\
G-rich sequence factor-1 (GRSF-1) & NM_22521 \\
Ornithine aminotransferase (Oat) & NM_022297 \\
Dimethylaminohydrolase 1 (Ddah1) & AJ243949 \\
mRNA for astrocytic phosphoprotein (PEA-15) & NM_020075 \\
Translation initiation factor 5 (Eif5) &
\end{tabular}

Rat MCs were incubated for $4 \mathrm{~h}$ in the presence or absence of $500 \mu \mathrm{M}$ $S$-nitroso-glutathione. The subtraction library was generated using CDNA representational difference analysis consisting of upregulated pool $A$ or downregulated pool B genes. PCR products were cloned and sequenced as described in the materials and methods section. Sequence analysis was performed and compared to public databases using BLAST.

were identified as sequences representing upregulated genes, and 28 clones from subtraction pool B were identified as sequences representing downregulated genes. The cDNA inserts varied in size from $130 \mathrm{bp}$ to $1.5 \mathrm{~kb}$. To test the differential expression of these cDNAs, two identical dot blots (data not shown) were prepared and hybridized with radiolabeled cDNA from pools $A$ and $B$ (summarized in Table 1). A total of 45 clones showed regulation in the dot blots. All 45 clones were sequenced and the sequence data were aligned against the GenBank nucleotide (rat genome) database at the National Center for Biotechnology Information (NIH, Bethesda, MD, USA) using Blastn to search for sequence matches. Seven gene sequences identified from pool A showed upregulation in dot blots and had $98-100 \%$ homology to different genes of diverse physiological relevance (Table 1). Eleven gene sequences from pool $B$ (downregulated genes) showed $98-100 \%$ homology to six well-characterized matrix-associated genes and seven genes with diverse biological significance (Table 1). Several sequences from both pools were homologous to cloning vector and ribosomal RNA gene sequences (data not listed).

\section{Exogenous NO donors downregulate mRNA expression of ECM-linked genes in MCs}

To validate the RDA findings predicting downregulation of CTGF and TSP-1, we analyzed total RNA extracted from spermine NONOate-stimulated human MCs (treated with $5 \mathrm{ng} / \mathrm{ml}$ TGF- $\beta 1$ and $30 \mathrm{~mm}$ glucose for $24 \mathrm{~h}$ prior to NO stimulation to create a pro-fibrotic environment for cells) by Northern blot analysis using gene-specific cDNA probes. Time- and dose-dependent downregulation of CTGF and TSP-1 mRNA (Figure 1A) was observed after treatment with $500 \mu \mathrm{M}$ spermine NONOate. Comparable time-dependent downregulation of CTGF and TSP-1 was observed when rat MCs were treated with 100-500 $\mu \mathrm{M}$ spermine NONOate, NOC-18 or SNAP (data not shown). COL1A2 mRNA in rat MCs was also time-dependently downregulated by $500 \mu \mathrm{M}$ spermine NONOate (Figure 1B), NOC-18 and SNAP (data not shown). We hypothesized that $\mathrm{NO}$ might affect the expression of additional matrix-associated genes. We therefore used quantitative RT-PCR to determine the changes in mRNA expression levels of COL1A1, COL1A2, CTGF and biglycan in human MCs. We observed dose- and time-dependent downregulation of gene expression of COL1A1, COL1A2, CTGF and biglycan (Figure 1C i-iv) in response to spermine NONOate stimulation.

\section{Exogenous NO donors downregulate TSP-1 and CTGF protein expression in MCs}

Two example genes, TSP-1 and CTGF, were selected to verify the effects of exogenous NO donors on protein expression. Quiescent human MCs were treated for $24 \mathrm{~h}$ with $5 \mathrm{ng} / \mathrm{ml}$ TGF- $\beta 1$ and $30 \mathrm{~mm}$ glucose. Increasing doses of spermine NONOate, SNAP and NOC-18 were used to stimulate the cultured cells for an additional 12 or $24 \mathrm{~h}$ in the same medium. After $24 \mathrm{~h}$ of incubation, conditioned media were harvested and TSP-1 protein concentrations were determined by ELISA. A significant $(p<0.001)$ dose- and time-dependent decrease in TSP-1 protein content was observed for cells treated with spermine NONOate, SNAP or NOC-18 at all time points and concentrations. The only exception was observed for 100, 250 and $500 \mu \mathrm{M}$ spermine NONOate at $12 \mathrm{~h}$ (Figure $2 \mathrm{~A}-\mathrm{C})$. To investigate CTGF protein expression, equal amounts of protein in conditioned media were subjected to SDS-PAGE. CTGF protein was then detected using a CTGF anti-human monoclonal antibody (FG-3019). 

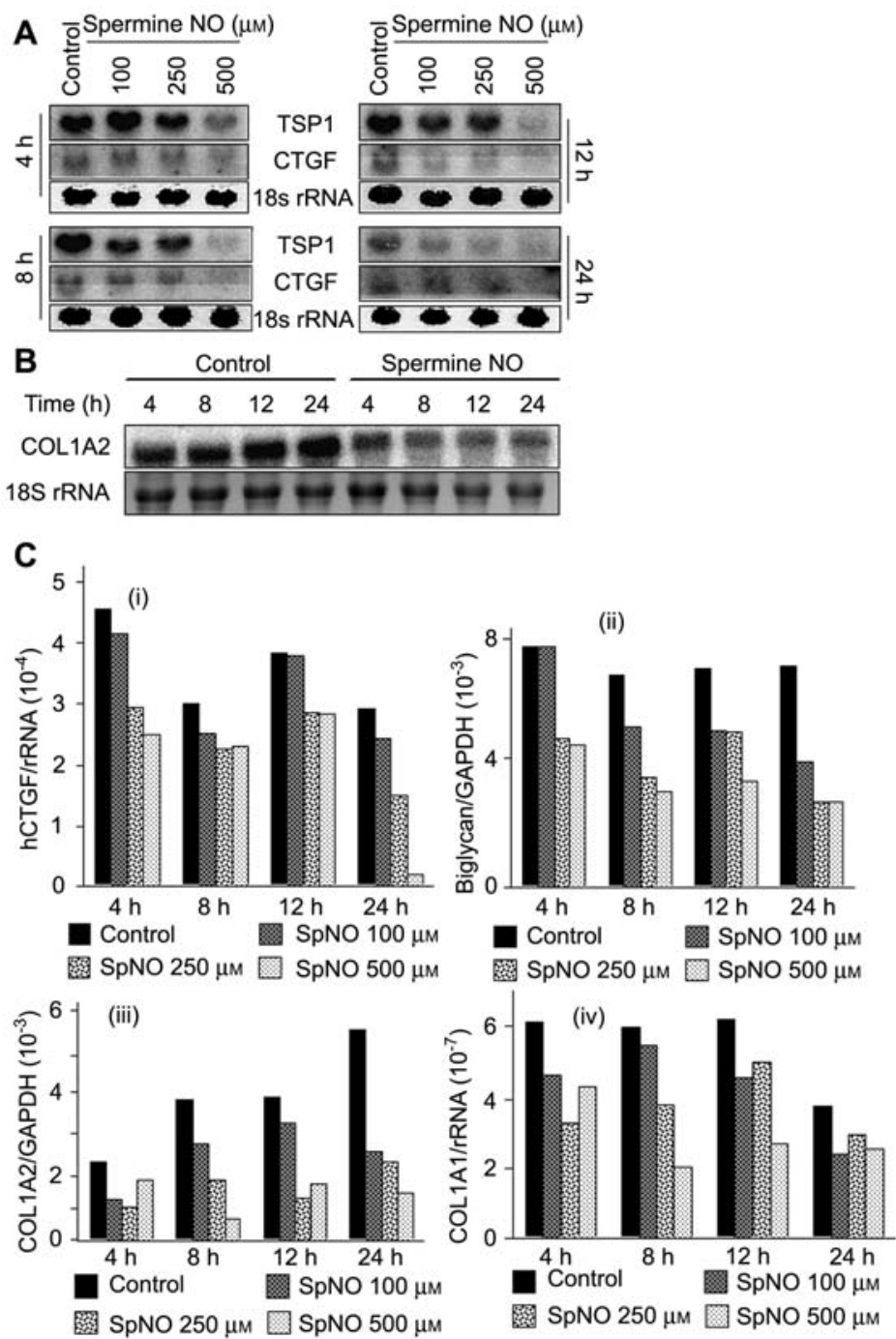

Figure 1 Exogenous NO donors downregulate mRNA expression of ECM genes in human mesangial cells.

Quiescent human (A) or rat (B) mesangial cells were incubated with medium containing $30 \mathrm{~mm}$ glucose and $5 \mathrm{ng} / \mathrm{ml}$ TGF- $\beta 1$ for $24 \mathrm{~h}$ before stimulation with or without spermine NONOate at the concentrations and time points indicated. Total RNA (15 $\mu \mathrm{g})$ was isolated and the expression levels of CTGF, TSP-1, COL1A2 and 18S rRNA were analyzed by Northern blotting (C). cDNA synthesized from $2 \mu \mathrm{g}$ of total RNA from quiescent human mesangial cells grown in serum-free medium containing $30 \mathrm{~mm}$ glucose and $5 \mathrm{ng} / \mathrm{ml}$ TGF$\beta 1$ for $24 \mathrm{~h}$ was subjected to real-time quantitative PCR using human RT-PCR fluorescent probes for CTGF, COL1A1, COL1A2, biglycan $(B G N), G A P D H$ and/or ribosomal RNA as described in the materials and methods section.

Strong CTGF protein expression was detected in the control sample, which was reduced in intensity in NOtreated samples (Figure 2D). Strong inhibition of CTGF protein expression was demonstrated in samples treated with $500 \mu \mathrm{M}$ spermine NONOate and NOC-18.

\section{INF $\gamma$ and BH4 stimulation of MCs leads to the production of endogenous NO, which is reversed by selective iNOS inhibitors}

To investigate whether a combination of interferon $\gamma$ (INF $\gamma$ ) and tetrahydro-L-biopterin (BH4, a NOS co-factor) can stimulate the release of $\mathrm{NO}$ and whether this phenomenon is reversible by selective iNOS inhibitors in MCs, rat and human quiescent MCs grown for $24 \mathrm{~h}$ were treated in medium containing $5 \mathrm{ng} / \mathrm{ml} \mathrm{TGF}-\beta 1$ and $30 \mathrm{~mm}$ glucose with $200 \mathrm{U} / \mathrm{ml}$ INF $\gamma$ and $10 \mu \mathrm{M} \mathrm{BH} 4$, or INF $\gamma$ alone for $0-24 \mathrm{~h}$ in the presence or absence of the iNOS inhibitors 1400W, L-NIL and L-NMMA. Media were harvested at different time points and assayed for the pres- ence or absence of nitrites by Griess assay. Nitrite concentrations in media from INF $\gamma$ - and $\mathrm{BH} 4$-stimulated cells were significantly higher $(7 \mu \mathrm{M} \pm \mathrm{SD} ; p<0.001)$ than in media from untreated cells $(2 \mu \mathrm{M} \pm \mathrm{SD}$; $p<0.001)$ in multiple experiments. There was a significant decrease $(p<0.01$ and 0.001$)$ in nitrite accumulation in media from cells treated with either L-NIL or 1400W (Figure 3A). Because of its potent effects, $1400 \mathrm{~W}$ was chosen as the candidate inhibitor of iNOS enzyme activity for subsequent experiments.

\section{Activation of iNOS by INF $\gamma$ and $\mathrm{BH} 4$ leads to} endogenously generated NO, which effectively downregulates CTGF, TSP-1, COL1A1, COL1A2 and biglycan mRNA in MCs

To demonstrate that INF $\gamma$ and $\mathrm{BH} 4$ stimulation of MCs leads to the endogenous release of $\mathrm{NO}$ by enzymatic activation of iNOS, and that this is in turn responsible for the downregulation of select matricellular genes, the 


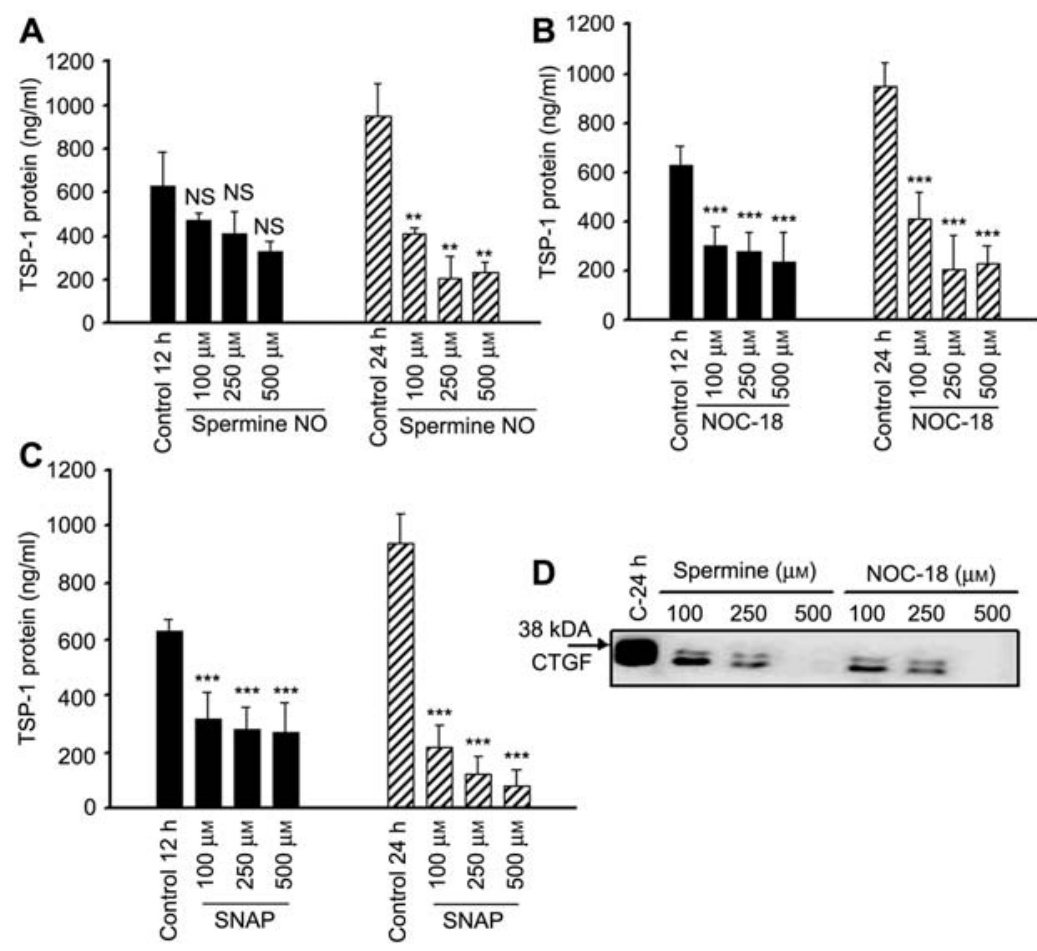

Figure 2 Exogenous NO donors downregulate TSP-1 and CTGF protein expression in human mesangial cells.

(A) Quiescent human mesangial cells were incubated with medium containing $30 \mathrm{~mm}$ glucose and $5 \mathrm{ng} / \mathrm{ml}$ TGF- $\beta 1$ for $24 \mathrm{~h}$ before stimulation with or without 100,250 and $500 \mu \mathrm{M}$ of (A) spermine NO, (B) NOC-18 and (C) SNAP for 12 and $24 \mathrm{~h}$. Conditioned media were collected after 12 and $24 \mathrm{~h}$ and secreted levels of TSP-1 were measured by ELISA as described in materials and methods. Data represent mean \pm SD of eight cultures for each condition. TSP-1 levels were significantly lower $\left({ }^{* \star} p<0.001\right)$ compared to untreated controls at all concentrations of spermine NONOate at $24 \mathrm{~h}, \mathrm{NOC}-18$ at 12 and $24 \mathrm{~h}$, and SNAP at 12 and $24 \mathrm{~h}$. (D) Quiescent human mesangial cells grown in medium containing $30 \mathrm{~mm}$ glucose and $5 \mathrm{ng} / \mathrm{ml}$ TGF- $\beta 1$ for $24 \mathrm{~h}$ were treated or not with the concentrations of spermine NONOate or NOC-18 indicated for $24 \mathrm{~h}$. Total protein was harvested and subjected to Western blot analysis with human anti-CTGF monoclonal antibody as described in materials and methods. Equal loading of protein samples was ensured by prequantification of protein levels by the Bradford method initially, and verified following separation of the proteins by Coomassie Brilliant Blue staining of the gels.

expression of iNOS was induced in MCs grown for $24 \mathrm{~h}$ in medium containing $5 \mathrm{ng} / \mathrm{ml}$ TGF- $\beta 1$ and $30 \mathrm{~mm}$ glucose with $200 \mathrm{U} / \mathrm{ml} \mathrm{INF} \gamma$ and $10 \mu \mathrm{M} \mathrm{BH} 4$, or INF $\gamma$ alone for $20 \mathrm{~h}$ in the presence or absence of $1400 \mathrm{~W}$. Conditioned media were assayed for the presence of nitrites using the Griess assay. Total RNA was harvested and used for Northern blot analysis to test for iNOS, CTGF and TSP-1 mRNA using gene-specific radioactively labeled CDNA probes. iNOS protein was assayed by Western blotting using polyclonal anti-iNOS antibodies. iNOS mRNA and protein expression was detected after $20 \mathrm{~h}$ of stimulation with INF $\gamma$ and $\mathrm{BH} 4$ in human (Figure $3 \mathrm{~B})$ and rat MCs (data not shown). A decrease in CTGF and TSP-1 mRNA levels was observed after the addition of IFN $\gamma$ or IFN $\gamma$ plus $\mathrm{BH} 4$, corresponding to nitrite release in the same set of experiments (Figure 3B). This decrease was reversed by the addition of $1400 \mathrm{~W}$.

To further demonstrate that endogenously produced $\mathrm{NO}$ in response to iNOS activation by INF $\gamma$ and $\mathrm{BH} 4$ can lead to downregulation of CTGF and COL1A1, as well as biglycan and COL1A2 (two additional ECM-associated genes), quiescent human MCs grown for $24 \mathrm{~h}$ in medium containing $30 \mathrm{~mm}$ glucose were treated with $200 \mathrm{U} / \mathrm{ml}$ INF $\gamma$ and $10 \mu \mathrm{M} \mathrm{BH} 4$, or INF $\gamma$ alone for $20 \mathrm{~h}$ in the presence of $1400 \mathrm{~W}$. Controls were not treated. Total RNA was subjected to RT-PCR analysis using gene-specific RT-PCR probes. Results showed a decrease in CTGF
(Figure 3C i), biglycan (Figure 3C ii), COL1A2 (Figure 3C iii) and COL1A1 (Figure 3C iv) MRNA in samples treated with INF $\gamma$ alone or INF $\gamma$ in combination with $\mathrm{BH} 4$. $1400 \mathrm{~W}$, a selective iNOS inhibitor, rescued the downregulatory effects of the combination of INF $\gamma$ and $\mathrm{BH} 4$, indicating that the effects are NO-specific. Interestingly, the effects of INF $\gamma$ alone were not rescued by $1400 \mathrm{~W}$ (Figure 3C).

\section{Downregulation of CTGF by NO is not mediated by changes in mRNA stability}

To determine the effect of NO on CTGF mRNA stability, Northern blot analysis of CTGF mRNA in human MCs was performed after treatment with actinomycin D $(10 \mathrm{ng} / \mathrm{ml})$ for up to $8 \mathrm{~h}$ in the presence or absence of $500 \mu \mathrm{M}$ spermine NONOate. The rate of decay of CTGF mRNA was of equivalent magnitude in cells grown in spermine NO-treated media (Figure 4A,B), and the message half-life was calculated to be less than $2 \mathrm{~h}$ in control and spermine NO-treated media (Figure 4C). We concluded that the decrease in the steady-state level of CTGF mRNA induced by spermine NO treatment in MCs is unlikely to be due to decreased mRNA stability, although a small component of message destabilization cannot be excluded. 

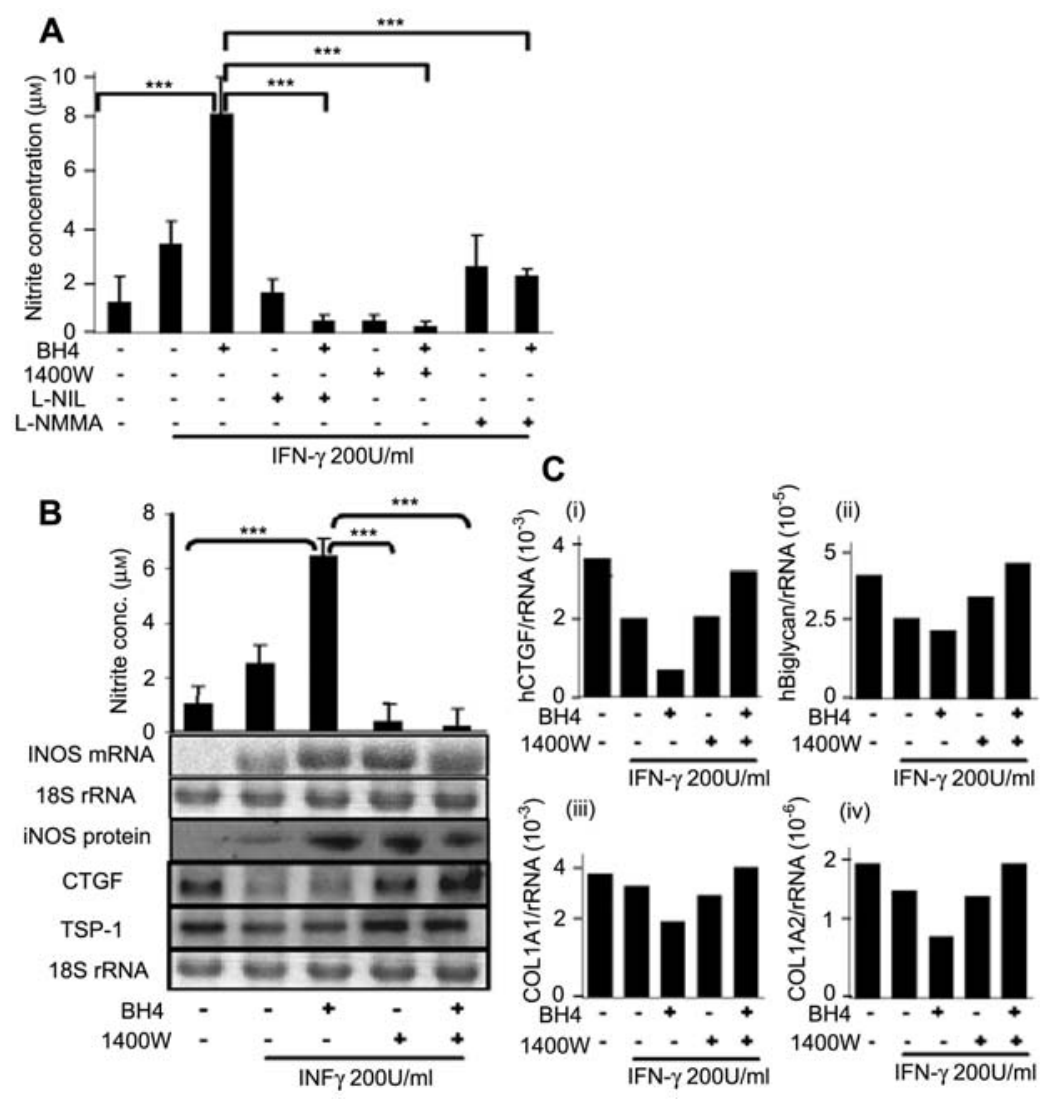

Figure 3 NO endogenously generated by the induction of iNOS with INF- $\gamma$ and BH4 downregulates the mRNA expression of different genes involved in matrix accumulation in human MCs.

(A) Human mesangial cells grown and stimulated under the conditions stated above were left untreated or treated in the presence of $200 \mathrm{U} / \mathrm{ml} \mathrm{INF-} \gamma$ or $200 \mathrm{U} / \mathrm{ml}$ INF- $\gamma$ plus $10 \mu \mathrm{M} \mathrm{BH} 4$, with or without $200 \mu \mathrm{M}$ of $1400 \mathrm{~W}, 100 \mu \mathrm{M}$ L-NIL, or $250 \mu \mathrm{M} \mathrm{L-NMMA}$. After $20 \mathrm{~h}$, media were collected and assayed for nitrite content using the Griess assay. Data shown are mean \pm SD of three independent experiments; ${ }^{* \star *} p<0.001$ compared to cells treated with $200 \mathrm{U} / \mathrm{ml} \mathrm{INF- \gamma}$ plus $10 \mu \mathrm{M} \mathrm{BH} 4$. (B) Quiescent human MCs grown in medium containing $30 \mathrm{~mm}$ glucose and $5 \mathrm{ng} / \mathrm{ml}$ TGF- $\beta 1$ for $24 \mathrm{~h}$ were left untreated or treated with $200 \mathrm{U} / \mathrm{ml} \mathrm{INF-} \gamma, 200 \mathrm{U} / \mathrm{ml}$ INF- $\gamma$ plus $10 \mu \mathrm{M} \mathrm{BH} 4,200 \mathrm{U} / \mathrm{ml} \mathrm{INF- \gamma}$ plus $200 \mu \mathrm{M} 1400 \mathrm{~W}$ or $200 \mathrm{U} / \mathrm{ml}$ INF- $\gamma$ plus $10 \mu \mathrm{M} \mathrm{BH} 4$ plus $200 \mu \mathrm{M} 1400 \mathrm{~W}$ for $20 \mathrm{~h}$. Total RNA extracted from unstimulated and stimulated cells was probed for CTGF, TSP-1, iNOS and 18S rRNA in a Northern blot analysis. Whole-cell lysate from parallel experiments with similar conditions was used for the determination of iNOS protein. In this case, equal amounts of total protein were subjected to SDS-PAGE and probed with an anti-rabbit iNOS polyclonal antibody as described in the materials and methods section. For determination of the nitrite content, conditioned media from the same set of experiments were subjected to the Griess assay at the time of termination of the experiments $(20 \mathrm{~h})$. Data shown are the mean of three independent experiments $\left(7 \mu \mathrm{M} \pm \mathrm{SD}\right.$; $\left.{ }^{\star \star \star} p<0.001\right)$ compared to medium from untreated cells $\left(2 \mu \mathrm{M} \pm \mathrm{SD} ;{ }^{\star \star \star} p<0.001\right)$. (C) cDNA synthesized from $2 \mu \mathrm{g}$ of total RNA from the same set of experiments in (B) was subjected to real-time quantitative PCR using human RT-PCR fluorescent probes for CTGF, COL1A1, COL1A2, biglycan (BGN), GAPDH and/or ribosomal RNA as described in the materials and methods section.

\section{NO inhibits putative CTGF promoter activity in MCs}

To confirm that the decrease in the steady-state level of CTGF mRNA induced by exogenous NO is due to a decrease in gene transcription rate, promoter-reporter gene assays using a putative CTGF promoter/SEAP reporter construct were performed. Human MCs were transiently transfected with a $-805 /+17-b p$ putative human CTGF promoter construct (pCTGF-SEAP). Relative SEAP activity was measured $72 \mathrm{~h}$ after addition of 10,100 or $250 \mu \mathrm{M}$ NOC-18. Reporter analysis showed a significant decrease (Figure $5 \mathrm{~A}$ ) in relative SEAP activity $(p<0.001)$ in NOC-18-treated cells compared to untreated controls. Stimulation of pCTGF-SEAP-transfected cells with increasing doses of DetaNONOate and spermine NONOate (Figure 5B) also showed a significant decrease in reporter protein (SEAP) expression $(p<0.001)$. pSEAP-SV40-transfected human MCs stimu- lated with different doses of NOC-18, and used as a positive control showed surprisingly significant upregulation of relative SEAP activity $(p<0.01)$ compared to untreated control cells (Figure 5A), suggesting an effect on the SV40 minimal promoter. These data demonstrate that exogenously added NO can apparently act at the promoter level to suppress TGF- $\beta 1$ - and glucose-induced CTGF expression.

\section{Discussion}

The results detailed here expand our understanding of the complex role of NO in regulating the expression of genes in kidney MCs. The data presented confirm the results of other investigators (Murphy et al., 1999; Keil et al., 2002; Shi-Wen et al., 2006) and include a series of unique observations that provide additional insight into 


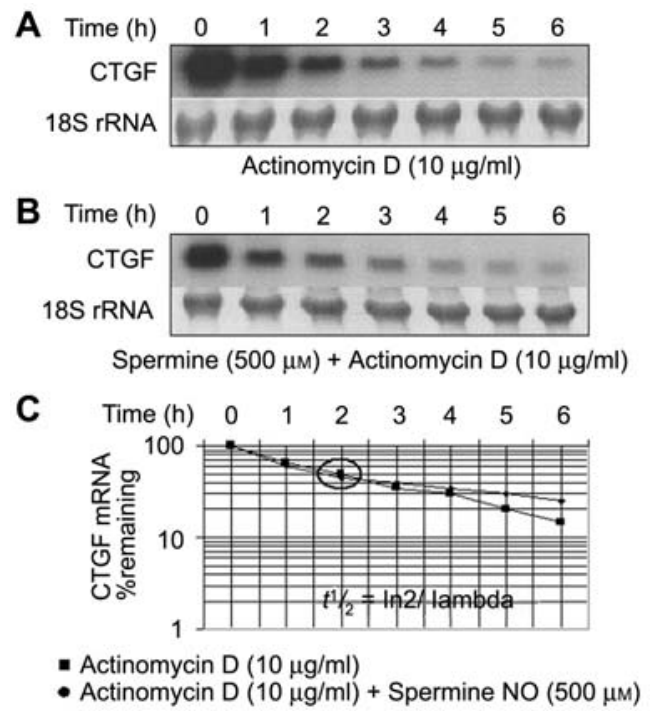

Figure 4 CTGF mRNA stability is not affected by NO.

$(A, B)$ Quiescent human MCs grown in serum-free medium containing $30 \mathrm{~mm}$ glucose and $5 \mathrm{ng} / \mathrm{ml}$ TGF- $\beta 1$ for $24 \mathrm{~h}$ were exposed to actinomycin $D$ alone $(10 \mu \mathrm{g} / \mathrm{ml})$ or to actinomycin $D$ $(10 \mu \mathrm{g} / \mathrm{ml})$ and spermine NO $(500 \mu \mathrm{M})$. Total RNA from the stimulated cells was subjected to Northern blot hybridization using radiolabeled CTGF probes. (C) Graphic profile of CTGF mRNA decay after treatment with actinomycin $D$ for unstimulated cells $(\square)$ or cells stimulated with $500 \mu \mathrm{M}$ spermine NONOate (๑). Measurements at time 0 for actinomycin $D$ treatment were assigned a relative value of $100 \%$. The average half-life of the CTGF message was calculated to be approximately $2 \mathrm{~h}$ in both treated and untreated samples.

the biological role of $\mathrm{NO}$ in moderating gene expression in a fibrotic setting. Despite the limitations of RDA (such as its low throughput), we were successful in identifying several important ECM-associated genes downregulated by GSNO treatment of glomerular MCs.

To confirm the RDA results, we used sublethal doses of a series of additional $\mathrm{NO}$ donors and a human MC line to verify the universality of changes in gene expression elicited by GSNO treatment (Bannenberg et al., 1995) in rat MCs. Human MCs were conditioned to maintain amplified levels of matrix-associated genes and proteins by treatment with TGF- $\beta$ and high levels of glucose, thus mimicking a fibrotic environment. Similar to previous observations in GSNO-stimulated MCs (Rupprecht et al., 2000), no cytotoxicity was observed either with GSNO or other NO donors used in this study, except when NO donor concentrations $>250 \mu \mathrm{M}$ were used in the inherently stressful promoter transfection experiments.

Among the gene targets of $\mathrm{NO}$ identified in $\mathrm{MC}$ experiments were type I collagen COL1A1 and COL1A2, biglycan, CTGF and TSP-1. Type I collagen is a major component of the ECM, which is synthesized by fibroblasts and vascular smooth muscle cells and in the kidney by glomerular MCs. Type I collagen is considered to be centrally involved in progressive glomerular ECM accumulation and is associated with chronic sclerotic processes (Ortega-Velazquez et al., 2004). NO has previously been shown to inhibit the production of major matrix components such as collagen, fibronectin, and laminin in rat MCs (Trachtman et al., 1995; Craven et al., 1997). The results presented here demonstrate that
A

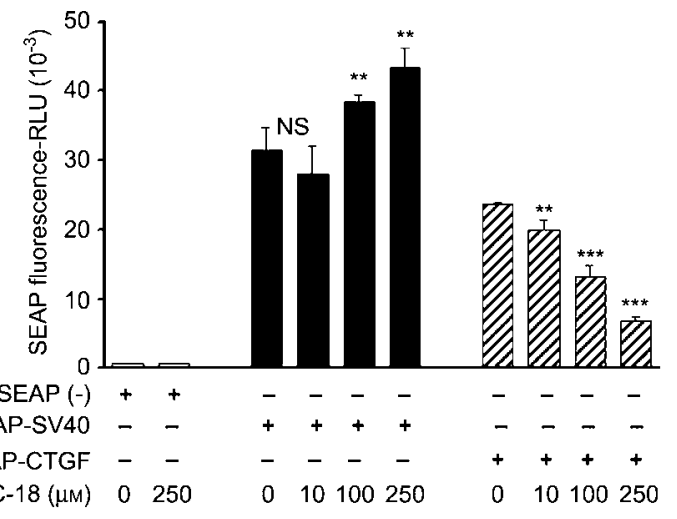

B

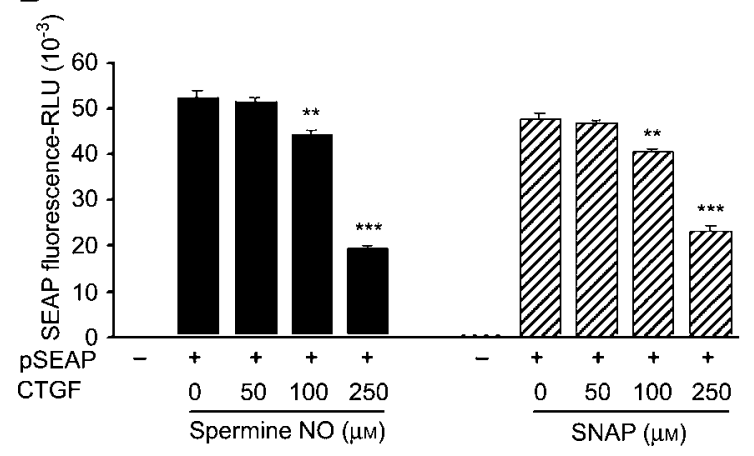

Figure 5 NO inhibits putative CTGF promoter activity in a SEAP reporter assay.

(A) Human MCs grown for $8 \mathrm{~h}$ in DMEM containing 10\% FCS were transfected with a putative CTGF promoter $(-805$ to +17$) /$ SEAP reporter plasmid (1.5 $\mu \mathrm{g} /$ well). After transfection, cells were incubated in serum-free medium containing $30 \mathrm{~mm}$ glucose and $5 \mathrm{ng} / \mathrm{ml}$ TGF- $\beta 1$ for $24 \mathrm{~h}$ with or without 10,100 and $250 \mu \mathrm{M}$ NOC-18. Cells were co-transfected with SV40/SEAP positive control plasmid $(0.5 \mu \mathrm{g} /$ well) and treated with $250 \mu \mathrm{M}$ NOC-18 to show that NO does not exhibit any downregulatory effects on a different and unrelated promoter. (B) Under similar conditions, human MCs were transfected with CTGF promoter/SEAP reporter or SEAP (-) plasmids ( $1.5 \mu \mathrm{g} /$ well). Control cells were transfected with a $1.5 \mu \mathrm{g} /$ well SEAP reporter plasmid having no promoter [SEAP (-)]. Transfected cells were left untreated or treated with 50,100 or $250 \mu \mathrm{M}$ spermine NONOate or SNAP for $48 \mathrm{~h}$, as indicated. Data represent the mean \pm SD of three independent experiments with triplicate wells for each condition in each setting (A,B). SEAP activity in relative light units was measured in conditioned media after $48 \mathrm{~h}$ using a SEAP fluorescent assay kit as described in the materials and methods section. All experiments were performed in 12-well plates. Values expressed show significant differences in expression $\left({ }^{\star *} p<0.01\right.$ and $\left.{ }^{* \star *} p<0.001\right)$ relative to cells transfected with untreated or untreated and co-transfected putative CTGF-promoter/SEAP reporter plasmids.

genes linked to the structural component of ECM, such as type I collagen, are targets of NO-mediated downregulation. This may help to explain in part the role of NO in tissue remodeling in chronic inflammatory kidney diseases.

TSP-1 is an important ECM protein that has been shown to be an activator of TGF- $\beta$ in vivo (Crawford et al., 1998; Daniel et al., 2004). TSP-1 is involved in diverse biological activities that may be attributable to the multiple functional domains and different cell-surface receptors associated with the protein. In addition, TSP-1 can act as either a soluble or matrix-bound factor. In the stud- 
ies detailed here, treatment of MCs with high levels of glucose and TGF- $\beta$ resulted in increased basal expression of TSP-1, which was in turn downregulated by NO stimulation. This observation is consistent with the results of Wang et al. (2002). Our results further demonstrate that different $\mathrm{NO}$ donors act in a time- and concentration-dependent manner to prevent increases in steady-state TSP-1 mRNA. We also demonstrated a decrease in TSP-1 protein levels in human MCs upon exposure to high levels of glucose and TGF- $\beta$. This suggests that NO may help to regulate the TSP-1 mRNA levels that result from the 'fibrotic' environment mimicked by treatment with high levels of glucose and TGF- $\beta$.

The observation that biglycan (BGN) is also a target of exogenous or endogenous NO in human MCs is consistent with studies by (Schaefer et al., 2003), who reported that $B G N$ is an NO-regulated gene in rat MCs both in vitro and in vivo and that it is involved in the adhesion, proliferation and survival of MCs. Biglycan is a member of small, leucine-rich repeat glycoproteins/proteoglycans (SLRPs), which are thought to play a role as organizers of ECM (Hocking et al., 1998). Overexpression of BGN is found in advanced stages of glomerulosclerosis (Davies, 1995). BGN is capable of inhibiting the proliferation of MCs induced by PDGF-B, a major mitogenic growth factor frequently involved in glomerular disease (Blom et al., 2001; Schaefer et al., 2003).

In our studies with CTGF, we observed a dose- and time-dependent decrease in mRNA and protein expression with a series of $\mathrm{NO}$ donors. Downregulation of CTGF mRNA was also evident when endogenous NO release was stimulated by the activation of iNOS with INF $\gamma$ and $\mathrm{BH} 4$ in human MCs. These data are consistent with the observations of Keil et al. (2002). CTGF, a secreted protein (Kireeva et al., 1997; Chen et al., 2002) is a member of the CCN (CTGF, Cyr61, and Nov) family of proteins that promote angiogenesis, cell migration, and cell adhesion (Fan et al., 2000; Ivkovic et al., 2003). CTGF upregulation is an important component in the pathogenesis of mesangial matrix accumulation and progressive glomerulosclerosis, acting downstream of TGF- $\beta$ (Riser et al., 2000). CTGF is induced by TGF- $\beta$ in fibroblasts and acts synergistically with TGF- $\beta$ to promote sustained fibrosis (Chen et al., 2002). The induction of fibrosis by high levels of glucose is thought to be mediated, at least in part, by TGF- $\beta$. However, increased CTGF expression has also been observed in cultured mesangial cells under high glucose conditions (Gupta et al., 2000; Wahab et al., 2001; Huang et al., 2003).

Our transient transfection studies using a CTGF-SEAP reporter construct suggest that exogenously added NO acts at the transcriptional level to downregulate glucoseand TGF- $\beta$-mediated CTGF gene expression in both rat and human MCs. These results were supported by mRNA half-life experiments that showed that NO has a limited effect on CTGF mRNA stability. CTGF expression has been shown to be differentially regulated, depending on the cell type and condition; however, our data are in part consistent with observations by Chen et al. (2002) confirming the induction of basal CTGF promoter activity in MCs treated with TGF- $\beta$.

Our findings provide evidence that $N O$ is capable of downregulating COL1A2, COL1A2, BGN, CTGF and
TSP-1 gene expression in MCs. Using a series of NO donors, we could show that for CTGF this regulation occurred at the transcriptional level in a time- and concentration-dependent manner. Our data further demonstrate that the reduction in mRNA levels by endogenously generated NO was not caused by a direct cytokine effect, since $1400 \mathrm{~W}$, a selective inhibitor of iNOS, counteracted the NO effect. The exact mechanism and NO-responsive cis-regulatory elements in the CTGF promoter are yet to be identified. Previous work carried out by our group suggests that the Egr-1 transcription factor is regulated by NO (Rupprecht et al., 2000) and that Egr-1 may be important for MC proliferation and matrix accumulation.

The results presented here, together with our previous observation that NO has an antiproliferative effect on MCs, suggest an important role for NO in regulating the expression of profibrotic genes. Moreover, treatment strategies employing optimal intervention with exogenous NO donors might prove beneficial in certain disease conditions with glomerular fibrosis.

\section{Materials and methods}

\section{Reagents}

S-Nitroso-L-glutathione (GSNO), spermine NONOate, 1400W (dihydrochloride), L-NMMA (citrate), L-NIL and tetrahydro-Lbiopterin (dihydrochloride) $(\mathrm{BH} 4 \cdot 2 \mathrm{HCl})$ were purchased from Cayman Chemicals (Ann Arbor, MI, USA). SNAP, NOC-18, and glutathione (GSH) were obtained from Calbiochem (Darmstadt, Germany). Human and rat recombinant interferon $\gamma$ (INF- $\gamma$ ), rat recombinant interleukin-1 $\beta$ (IL-1 $\beta$ ), rat recombinant tumor necrosis factor $\alpha$ (TNF- $\alpha)$ and human transforming growth factor-1 $\beta$ (TGF- $\beta 1$ ) were from Peprotech Inc. (Rocky Hill, NJ, USA). D-(+)-Glucose solution was from Sigma-Aldrich (St. Louis, MO, USA). Polyclonal anti-rabbit iNOS antibody was from Cayman Chemicals. Human monoclonal anti-CTGF antibody (FG3019) was from FibroGen Inc. (South San Francisco, CA, USA). Bovine serum albumin (BSA) fraction $V$ was from Roche (Mannheim, Germany). Tri reagent was from Molecular Research Center Inc. (Cincinnati, OH, USA); Griess Reagent System was from Promega (Madison, WI, USA); NuPAGE 4-12\% Bis-Tris gels were from Invitrogen Life Technologies (Carlsbad, CA, USA); polyvinylidine difluoride (PVDF) membranes from Bio-Rad (Munich, Germany); Bright Star positively charged nylon membranes were from Ambion (Austin, TX, USA); Great EscAPe fluorescent SEAP Detection kit was from BD Biosciences (San Jose, CA, USA); SuperFect Transfection Reagent, EndoFree Plasmid Max kit, RNeasy mini kit and RNase-Free DNase were from Qiagen (Hilden, Germany); and Human TSP-1 EIA Kit was from PromoKine (PromoCell $\mathrm{GmbH}$, Heidelberg, Germany). Restriction enzymes were from Roche Diagnostics (Penzberg, Germany).

\section{Cell culture}

Rat MCs were cultured as described by Pfeilschifter (1991). Passages 9-15 were used for experiments. All media and supplements were purchased from Life Technologies (Basel, Switzerland). Human MCs were propagated from a cell line as described by Banas et al. (1999).

\section{Representational difference analysis}

RDA of cDNA was performed as described by Hubank and Schatz (1994) with the Clontech PCR-Select cDNA Subtraction 
Kit (Clontech, Palo Alto, CA, USA) according to the manufacturer's protocol. For this purpose, poly- $\mathrm{A}^{+} \mathrm{RNA}$ was extracted from GSNO-treated and control MCs and reverse-transcribed into cDNA. The cDNA containing the specific (differentially expressed) transcripts was termed the tester, and the reference cDNA, the driver. The tester and driver cDNAs were digested by Rsa I, a four-base-cutting restriction enzyme that yields blunt ends. The tester cDNA was then subdivided into two portions, and each was ligated with a different CDNA adaptor. The two adaptors had stretches of identical sequence to allow annealing of PCR primers once the recessed ends had been filled in. Two hybridizations were then performed. In the first, an excess of driver was added to each tester sample. The samples were then heat-denatured and allowed to anneal. The concentration of high- and low-abundance sequences was equalized among the single-strand molecules ligated to an adaptor because reannealing is faster for the more abundant molecules due to the second-order kinetics of hybridization. At the same time these molecules were significantly enriched for differentially expressed sequences. During the second hybridization, the two primary hybridization samples and an excess of driver were mixed together without denaturing. Now only the remaining equalized and subtracted single-strand tester cDNAs could re-associate and form hybrid double-strand tester molecules with different ends, which correspond to the sequences of the different adaptors. The entire population of molecules was then subjected to PCR to amplify the desired differentially expressed sequences. Only the molecules that had two different adaptors could be amplified exponentially. These were the equalized, differentially expressed sequences. A secondary PCR amplification was performed using nested primers to further reduce any background PCR products and enrich for differentially expressed sequences.

For dot blot analysis to confirm differential expression of identified genes, equal amounts of cloned cDNAs were dotted twice onto nylon membranes (Amersham LifeScience, Little Chalfont, UK) as recommended by Clontech. The membranes were airdried and hybridized with $\left[\alpha^{32} \mathrm{P}\right] \mathrm{dCTP}$-labeled forward- and reverse-subtracted cDNA probes of the GSNO-treated and untreated mRNA populations. Blots were exposed to Kodak Biomax MS or MR films (Eastman Kodak Company, Rochester, NY, USA) at $-80^{\circ} \mathrm{C}$. Clones with confirmed differential expression in the dot blot analysis were used for further tests in Northern blot analysis.

For nitrite assay, conditioned media after stimulation with different NO donors or cytokines were collected over $24 \mathrm{~h}$ and nitrite concentrations were measured using a colorimetric assay with the Griess reagent. Absorbance at $550 \mathrm{~nm}$ was measured in GENios Plus Microtiter plate reader (Tecan, Grödig, Austria) using XFluor4 software.

\section{Northern blot analysis}

Total RNA was isolated by Tri Reagent or an RNeasy kit according to the manufacturer's instructions. Total RNA $(15 \mu \mathrm{g})$ was subjected to electrophoresis on $1 \%$ formaldehyde agarose gels and transferred to positively charged Bright Star nylon membranes by downward alkaline transfer using $0.01 \mathrm{~N} \mathrm{NaOH}$. Blots were hybridized in ExpressHyb solution (Clontech) with $2 \times 10^{6} \mathrm{cpm} / \mathrm{ml}\left[\alpha^{32} \mathrm{P}\right] \mathrm{dCTP}$-labeled cDNA probes prepared using a Prime-It ${ }^{\circledR}$ RmT Random Primer Labeling Kit, Single-Use dCTPLabeling Reactions (Stratagene Europe). Probes for 18S rRNA, CTGF and COL1A2 were obtained by restriction digestion of RDA clones. The probe for TSP-1 (pTS-33) was purchased from ATCC (Manassas, VA, USA), which yields a full-length cloned TSP-1 cDNA fragment of $1.29 \mathrm{~kb}$ after restriction digestion with EcoRI. Membranes were either exposed to a Kodak Bio Max Xray film or visualized after exposure to a Phosphorimager screen and quantified by Image quantitation software (IQMac v 1.2) pro- vided with the Phosphoimager Strom 840 (Molecular Dynamics, Sunnyvale, CA, USA). X-Ray film blots were analyzed after scanning by ImageJ version 1.32j image quantitation software $(\mathrm{NIH})$.

\section{Western blot analysis}

Anti-iNOS rabbit polyclonal antibody from Cayman Chemicals was used at a dilution of 1:1000. Anti-CTGF human monoclonal anti-CTGF antibody was a gift from FibroGen, Inc. and used at a 1:250 dilution. Equal loading of cell lysates was ensured by prequantitation of protein levels by the Bradford method. Samples of $20 \mathrm{mg}$ were subjected to electrophoresis through a NuPAGE $4-12 \%$ Bis-Tris gel. After electrophoresis, proteins were further visualized using a SuperSignal Chemiluminescent kit (Pierce, Rockford, IL, USA). The gel was then transferred to PVDF membranes. Membranes were blocked overnight in 2\% BSA, incubated with anti-iNOS or anti-CTGF antibody for $1 \mathrm{~h}$ and with secondary horseradish peroxidase $\lg G$ antibody for $45 \mathrm{~min}$.

\section{ELISA}

Quantitation of thrombospondin-1 (TSP-1) protein secreted into the culture medium was performed using a competitive PromoKine Human TSP-1 enzyme immunoassay (EIA), which measures the natural and recombinant forms of TSP-1. Human mesangial cells were plated in 24-well culture plates at 70000 cells/well in growth medium and incubated for 1-3 days until subconfluency. Cells were then serum-starved for $24 \mathrm{~h}$ in Dulbecco's modified Eagle medium containing $30 \mathrm{~mm}$ D-glucose and $5 \mathrm{ng} / \mathrm{ml}$ TGF- $\beta 1$. Thereafter, cells were treated with 100,250 or $250 \mu \mathrm{M}$ spermine NONOate, SNAP or NOC-18 for 12 and $24 \mathrm{~h}$ in the same medium. The culture medium was then collected, clarified by centrifugation and used immediately for assay or stored at $-70^{\circ} \mathrm{C}$ until assayed. Samples were processed according to the manufacturer's instructions and the readings were performed at $490 \mathrm{~nm}$ in a GENios Plus Microtiter plate reader (Tecan) using XFluor4 software, until the OD of the growth medium reached 1.6. At this time point, $20 \mu \mathrm{l}$ of stop solution was added to each well and the plate was read again. A standard curve with recombinant TSP-1 protein standard was run at each setting. Reverse transcription was performed for $60 \mathrm{~min}$ at $42^{\circ} \mathrm{C}$ in a volume of $20 \mu \mathrm{l}$ using a modified Moloney-murine leukemia virus (MMLV) reverse transcriptase (Superscript and respective buffer; Life Technologies, Karlsruhe, Germany). This was performed in the presence of $1 \mathrm{mM}$ dNTPs (Amersham Pharmacia, Freiburg, Germany), $40 \mathrm{U}$ of RNase inhibitor (RNasin; Promega, Mannheim, Germany), $2 \mu$ l of dithiothreitol (DTT; Life Technologies), $2 \mu \mathrm{l}$ of random hexamers (Roche), and $7 \mu \mathrm{l}$ of the above RNA solution.

\section{Real-time quantitative RT-PCR}

Real-time RT-PCR was performed on a TaqMan ABI 7700 Sequence Detection System (Applied Biosystems, Weiterstadt, Germany) using heat-activated Taq DNA polymerase (Amplitaq Gold, Applied Biosystems). After an initial hold of $2 \mathrm{~min}$ at $50^{\circ} \mathrm{C}$ and $10 \mathrm{~min}$ at $95^{\circ} \mathrm{C}$, the samples were cycled 40 times at $95^{\circ} \mathrm{C}$ for $15 \mathrm{~s}$ and $60^{\circ} \mathrm{C}$ for $60 \mathrm{~s}$. The cDNA content of each sample was compared with another sample according to the $\Delta \mathrm{Ct}$ technique. This procedure uses the formula $A_{0} / B_{0}=(1+E)\left(C t_{B}-C_{A}\right)$ where $A_{0}$ is the initial copy number of sample $A, B_{0}$ is the initial copy number of sample $\mathrm{B}, \mathrm{E}$ is the amplification efficiency, $\mathrm{Ct}_{\mathrm{A}}$ is the threshold cycle for sample $A$, and $C_{B}$ is the threshold cycle for sample B. The amplification efficiency was defined as 1 , as all analyses were performed during the same runs, including control dilution series. Similar amplification efficiencies for targets and housekeeping genes were demonstrated by analyz- 
ing serial cDNA dilutions showing an absolute value of the slope of log input cDNA amount versus $\triangle \mathrm{CT}$ (Ct housekeeping geneCt target) of $<0.1$.

Commercially available human TaqMan Gene Expression assays with the following GenBank accession numbers and/or probe sequences were purchased from Applied Biosystems to perform RT-PCR: collagen type I $\alpha 1$ (COL1A1; NM_000088), 5'ACG AAG ACA TCC CAC CAA TCA CCT-3'; collagen type I $\alpha 2$ (COL1A2; NM_000089), 5'-TGG TCC AGC TGG CCC TCC TGG CAA-3'; biglycan (BGN; NM_001711), 5'-CCC TCT CCA GGT CCA TCC GCC AT-3'; and GAPDH (M33197); connective tissue growth factor (CTGF; NM_001901), sense primer 5'-ACG AGC CCA AGG ACC AAA C-3', antisense primer 5'-TCT GGG CCA AAC GTG TCT TC-3', fluorescently labeled probe 5'-TCG GTA AGC CGC GAG G-3'; inducible nitric oxide synthase (NOS2; NM_000625), sense primer 5'-ACA ACA GTA ACC TAC CAA CTG ACG G-3', antisense primer 5'-CCT CCC AAT GCA GCG TG-3', fluorescently labeled probe 5'-TGA GCT CAT CTT CGC CAC CAA GCA-3'. All these assay reagents do not amplify genomic DNA. This was verified using genomic human DNA samples. Controls consisting of $\mathrm{ddH}_{2} \mathrm{O}$ were negative in all runs.

\section{Message stability assay}

Quiescent human MCs grown in serum-free medium containing $30 \mathrm{~mm}$ glucose and $5 \mathrm{ng} / \mathrm{ml}$ TGF- $\beta 1$ for $24 \mathrm{~h}$ were exposed to actinomycin $D$ alone $(10 \mu \mathrm{g} / \mathrm{ml})$ or to actinomycin $D(10 \mu \mathrm{g} / \mathrm{ml})$ and spermine NO $(500 \mu \mathrm{M})$. Total RNA from stimulated cells (between 0 and 6 h) was subjected to Northern blot hybridization using radiolabeled probes for CTGF and $18 \mathrm{~S}$ rRNA to measure the rate of decay of CTGF mRNA. Measurement of the CTGF/ $18 S$ rRNA ratio at time $=0$ for actinomycin $D$ treatment in cells cultured in $500 \mu \mathrm{M}$ spermine NONOate was assigned a relative value of $100 \%$. The half-life was calculated according to the equation: $t_{1 / 2}=\ln 2 / \lambda$, where $\ln$ is the natural logarithm and $\lambda$ is the rate of decay of the message.

\section{Transient transfections and SEAP assay}

Rat or human MCs grown for $8 \mathrm{~h}$ to $50 \%$ confluence in DMEM containing $10 \%$ FCS were transfected with a putative CTGF promoter $(-805$ to +17$) /$ SEAP reporter plasmid pCTGF-SEAP (FibroGen, Inc.). Transfections were carried out using Superfect transfection reagent (Qiagen) at a DNA/Superfect ratio of 1:2, i.e., $1.5 \mu \mathrm{g}$ of plasmid DNA and $3 \mu \mathrm{l}$ of Superfect per well in a 12 -well plate. After transfection, cells were incubated in serumfree medium containing $30 \mathrm{~mm}$ glucose and $5 \mathrm{ng} / \mathrm{ml}$ TGF- $\beta 1$ for up to $48 \mathrm{~h}$ with or without 10,100 and $250 \mu \mathrm{M}$ NOC-18, spermine NONOate or SNAP. In co-transfection experiments, cells were transfected with $1.5 \mu \mathrm{g} /$ well SEAP reporter plasmid with no promoter [PSEAP (-)] as a negative control. Cells were transfected with pSV40/SEAP positive control plasmid $(0.5 \mu \mathrm{g} / \mathrm{well})$ as a positive control. In the positive control experiments, cells were additionally treated with $50-250 \mu \mathrm{M} \mathrm{NOC}-18$ to show that the control promoter activity was at least not downregulated by NO. SEAP protein was measured without any dilution of the conditioned media using a Great EScAPe SEAP Fluorescent detection kit (BD Biosciences) according to the manufacturer's instructions. The assay was performed in BD Falcon Microtest 96-well Optilux assay plates with black walls, a clear bottom and a tissue culture surface (BD Biosciences). Plates were read in a GENios Plus Microtiter plate reader (Tecan) using XFluor4 software at excitation and emission wavelengths of 360 and $449 \mathrm{~nm}$, respectively. Suitable standards were used to stay within the linear range of the assay as described in the manufacturer's protocol. Relative SEAP activity is determined as fluorescent units. Experiments were performed multiple times and values are represented as mean $\pm \mathrm{SD}$.

\section{Statistical analysis}

All results are expressed as mean \pm SD unless otherwise stated. Student's unpaired t-test was used for statistical analyses. Values of $p<0.05$ were considered statistically significant.

\section{Acknowledgments}

We gratefully acknowledge the support of FibroGen Inc. (South San Francisco, CA, USA) in providing putative CTGF promoter constructs and anti-CTGF monoclonal antibody. This work was supported by research grants from the German Research Foundation (DFG, Ru 446/2-1) to HR and (SFB 571 C2) to PJN.

\section{References}

Banas, B., Luckow, B., Moller, M., Klier, C., Nelson, P.J., Schadde, E., Brigl, M., Halevy, D., Holthofer, H., Reinhart, B., and Schlondorff, D. (1999). Chemokine and chemokine receptor expression in a novel human mesangial cell line. J. Am. Soc. Nephrol. 10, 2314-2322.

Bannenberg, G., Xue, J., Engman, L., Cotgreave, I., Moldeus, P., and Ryrfeldt, A. (1995). Characterization of bronchodilator effects and fate of S-nitrosothiols in the isolated perfused and ventilated guinea pig lung. J. Pharmacol. Exp. Ther. 272, 1238-1245.

Blatter, L.A. and Wier, W.G. (1994). Nitric oxide decreases [ $\left.\mathrm{Ca}^{2+}\right]$ in vascular smooth muscle by inhibition of the calcium current. Cell Calcium 15, 122-131.

Blom, I.E., van Dijk, A.J., Wieten, L., Duran, K., Ito, Y., Kleij, L., deNichilo, M., Rabelink, T.J., Weening, J.J., Aten, J., and Goldschmeding, R. (2001). In vitro evidence for differential involvement of CTGF, TGF $\beta$, and PDGF-BB in mesangial response to injury. Nephrol. Dial. Transplant. 16, 1139-1148.

Bogdan, C. (2001). Nitric oxide and the regulation of gene expression. Trends Cell Biol. 11, 66-75.

Chen, Y., Blom, I.E., Sa, S., Goldschmeding, R., Abraham, D.J., and Leask, A. (2002). CTGF expression in mesangial cells, involvement of SMADs, MAP kinase, and PKC. Kidney Int. 62, 1149-1159.

Craven, P.A., Studer, R.K., Felder, J., Phillips, S., and DeRubertis, F.R. (1997). Nitric oxide inhibition of transforming growth factor $\beta$ and collagen synthesis in mesangial cells. Diabetes 46 , $671-681$.

Crawford, S.E., Stellmach, V., Murphy-Ullrich, J.E., Ribeiro, S.M., Lawler, J., Hynes, R.O., Boivin, G.P., and Bouck, N. (1998). Thrombospondin-1 is a major activator of TGF $\beta 1$ in vivo. Cell 93, 1159-1170.

Daniel, C., Wiede, J., Krutzsch, H.C., Ribeiro, S.M., Roberts, D.D., Murphy-Ullrich, J.E., and Hugo, C. (2004). Thrombospondin-1 is a major activator of TGF- $\beta$ in fibrotic renal disease in the rat in vivo. Kidney Int. 65, 459-468.

Davies, M. (1995). Glomerular cell proteoglycans, their possible role in progressive glomerular disease. Exp. Nephrol. 3, 122-126.

Fan, W.H., Pech, M., and Karnovsky, M.J. (2000). Connective tissue growth factor (CTGF) stimulates vascular smooth muscle cell growth and migration in vitro. Eur. J. Cell Biol. 79, 915-923.

Gabbai, F.B., Boggiano, C., Peter, T., Khang, S., Archer, C., Gold, D.P., and Kelly, C.J. (1997). Inhibition of inducible nitric oxide synthase intensifies injury and functional deterioration in autoimmune interstitial nephritis. J. Immunol. 159, 62666275.

Groves, J.T. and Wang, C.C. (2000). Nitric oxide synthase, models and mechanisms. Curr. Opin. Chem. Biol. 4, 687-695. 
Gupta, S., Clarkson, M.R., Duggan, J., and Brady, H.R. (2000). Connective tissue growth factor, potential role in glomerulosclerosis and tubulointerstitial fibrosis. Kidney Int. 58, 13891399.

Guzik, T.J., Korbut, R., and Adamek-Guzik, T. (2003). Nitric oxide and superoxide in inflammation and immune regulation. J. Physiol. Pharmacol. 54, 469-487.

Habib, R. (1975). Proceedings, Classification and anatomo-clinical correlations of glomerular nephropathies. Schweiz. Med. Wochenschr. 105, 1749-1758.

Hemish, J., Nakaya, N., Mittal, V., and Enikolopov, G. (2003). Nitric oxide activates diverse signaling pathways to regulate gene expression. J. Biol. Chem. 278, 42321-42329.

Hocking, A.M., Shinomura, T., and McQuillan, D.J. (1998). Leucine-rich repeat glycoproteins of the extracellular matrix. Matrix Biol. 17, 1-19.

Huang, S., Liu, F., Sha, Z., Fu, P., Yang, Y., Xu, Y., and Zhou, H. (2003). Effect of high glucose, angiotensin II and receptor antagonist Losartan on the expression of connective tissue growth factor in cultured mesangial cells. Chin. Med. J. (England) 116, 554-557.

Hubank, M. and Schatz, D.G. (1994). Identifying differences in mRNA expression by representational difference analysis of cDNA. Nucleic Acids Res. 25, 5640-5648.

Hubank, M., Bryntesson, F., Regan, J., and Schatz, D.G. (2004). Cloning of apoptosis-related genes by representational difference analysis of cDNA. Methods Mol. Biol. 282, 255-273.

Ivkovic, S., Yoon, B.S., Popoff, S.N., Safadi, F.F., Libuda, D.E., Stephenson, R.C., Daluiski, A., and Lyons, K.M. (2003). Connective tissue growth factor coordinates chondrogenesis and angiogenesis during skeletal development. Development 130, 2779-2791.

Keil, A., Blom, I.E., Goldschmeding, R., and Rupprecht, H.D. (2002). Nitric oxide down-regulates connective tissue growth factor in rat mesangial cells. Kidney Int. 62, 401-411.

Kireeva, M.L., Latinkic, B.V., Kolesnikova, T.V., Chen, C.C., Yang, G.P., Abler, A.S., and Lau, L.F. (1997). Cyr61 and Fisp12 are both ECM-associated signaling molecules, activities, metabolism, and localization during development. Exp. Cell Res. 233, 63-77.

Murphy, M., Godson, C., Cannon, S., Kato, S., Mackenzie, H.S., Martin, F., and Brady, H.R. (1999). Suppression subtractive hybridization identifies high glucose levels as a stimulus for expression of connective tissue growth factor and other genes in human mesangial cells. J. Biol. Chem. 274, 5830-5834.

Oguma, S. (1988). A histometrical study on the development of three glomerulopathies. Kidney Int. 34, 102-108.

Ohno, M., Gibbons, G.H., Dzau, V.J., and Cooke, J.P. (1993). Shear stress elevates endothelial cGMP. Role of a potassium channel and G protein coupling. Circulation 88, 193-197.

Ortega-Velazquez, R., Gonzalez-Rubio, M., Ruiz-Torres, M.P., Diez-Marques, M.L., Iglesias, M.C., Rodriguez-Puyol, M., and Rodriguez-Puyol, D. (2004). Collagen I upregulates extracellular matrix gene expression and secretion of TGF- $\beta 1$ by cultured human mesangial cells. Am. J. Physiol. Cell Physiol. 286, C1335-C1343.
Pastorian, K., Hawel, L. III, and Byus, C.V. (2000). Optimization of cDNA representational difference analysis for the identification of differentially expressed mRNAs. Anal. Biochem. 283, 89-98.

Pfeilschifter, J. (1991). Platelet-derived growth factor inhibits cytokine induction of nitric oxide synthase in rat renal mesangial cells. Eur. J. Pharmacol. 208, 339-340.

Pfeilschifter, J. (2002). Nitric oxide triggers the expression of proinflammatory and protective gene products in mesangial cells and the inflamed glomerulus. Nephrol. Dial. Transplant. 17, 347-348.

Rangan, G.K., Wang, Y., and Harris, D.C. (2001). Pharmacologic modulators of nitric oxide exacerbate tubulointerstitial inflammation in proteinuric rats. J. Am. Soc. Nephrol. 12, 1696-1705.

Riser, B.L., Denichilo, M., Cortes, P., Baker, C., Grondin, J.M., Yee, J., and Narins, R.G. (2000). Regulation of connective tissue growth factor activity in cultured rat mesangial cells and its expression in experimental diabetic glomerulosclerosis. J. Am. Soc. Nephrol. 11, 25-38.

Rosenberg, H.G. (1986). Primary glomerular diseases (primary glomerulopathies). Pathol. Res. Pract. 181, 489-523.

Rupprecht, H.D., Akagi, Y., Keil, A., and Hofer, G. (2000). Nitric oxide inhibits growth of glomerular mesangial cells, role of the transcription factor EGR-1. Kidney Int. 57, 70-82.

Schaefer, L., Beck, K.F., Raslik, I., Walpen, S., Mihalik, D., Micegova, M., Macakova, K., Schonherr, E., Seidler, D.G., Varga, G., et al. (2003). Biglycan, a nitric oxide-regulated gene, affects adhesion, growth, and survival of mesangial cells. J. Biol. Chem. 278, 26227-26237.

Shi-Wen, X., Rodriguez-Pascual, F., Lamas, S., Holmes, A., Howat, S., Pearson, J.D., Dashwood, M.R., du Bois, R.M., Denton, C.P., Black, C.M., et al. (2006). Constitutive ALK5independent $\mathrm{C}$-Jun $\mathrm{N}$-terminal kinase activation contributes to endothelin-1 overexpression in pulmonary fibrosis, evidence of an autocrine endothelin loop operating through the endothelin A and B receptors. Mol. Cell. Biol. 26, 5518-5527.

Shultz, P.J. and Raij, L. (1992). Endogenously synthesized nitric oxide prevents endotoxin-induced glomerular thrombosis. J. Clin. Invest. 90, 1718-1725.

Stengel, B. (2003). [Epidemiology of chronic glomerular diseases]. Rev. Prat. 53, 1993-1997 (in French).

Trachtman, H., Futterweit, S., and Singhal, P. (1995). Nitric oxide modulates the synthesis of extracellular matrix proteins in cultured rat mesangial cells. Biochem. Biophys. Res. Commun. 207, 120-125.

Wahab, N.A., Yevdokimova, N., Weston, B.S., Roberts, T., Li, X.J., Brinkman, H., and Mason, R.M. (2001). Role of connective tissue growth factor in the pathogenesis of diabetic nephropathy. Biochem. J. 359, 77-87.

Wang, S., Shiva, S., Poczatek, M.H., Darley-Usmar, V., and Murphy-Ullrich, J.E. (2002). Nitric oxide and cGMP-dependent protein kinase regulation of glucose-mediated thrombospondin 1-dependent transforming growth factor-beta activation in mesangial cells. J. Biol. Chem. 277, 9880-9888.

Received August 29, 2006; accepted February 7, 2007 